\title{
Anterior knee pain after total knee arthroplasty: a narrative review
}

\author{
Wolf Petersen • Ingo Volker Rembitzki • Gerd-Peter Brüggemann • \\ Andree Ellermann • Raymond Best • Andreas Gösele- Koppenburg • \\ Christian Liebau
}

Received: 18 May 2013 / Accepted: 11 August 2013 /Published online: 22 September 2013

(C) The Author(s) 2013. This article is published with open access at Springerlink.com

\begin{abstract}
Anterior knee pain is one of the most common causes of persistent problems after implantation of a total knee replacement. It can occur in patients with or without patellar resurfacing. As a result of the surgical procedure itself many changes can occur which may affect the delicate interplay of the joint partners in the patello-femoral joint. Functional causes of anterior knee pain can be distinguished from mechanical causes. The functional causes concern disorders of inter- and intramuscular coordination, which can be attributed to preoperative osteoarthritis. Research about anterior knee pain has shown that not only the thigh muscles but also the hip and trunk stabilising muscles may be responsible for the development of a dynamic valgus malalignment. Dynamic valgus may be a causative factor for patellar maltracking. The mechanical causes of patello-femoral problems after knee replacement can be distinguished according to whether they increase instability in the joint, increase joint pressure or
\end{abstract}

W. Petersen $(\bowtie)$

Klinik für Orthopädie und Unfallchirurgie, Martin Luther

Krankenhaus, Caspar Theyß Strasse 27-31, 14193 Berlin Grunewald,

Germany

e-mail: w.petersen@mlk-berlin.de

I. V. Rembitzki • C. Liebau

Asklepios Harzkliniken GmbH Fritz-König-Stift, Bad Harzburg,

Germany

G.-P. Brüggemann

Deutsche Sporthochschule Köln, Institut für Biomechanik, Cologne, Germany

A. Ellermann

Arcus Sportklinik, Pforzheim, Germany

R. Best

Sportklinik, Stuttgart, Germany

A. G.-. Koppenburg

Cross Klinik Basel, Olympic Medical Center, Basel, Switzerland whether they affect the muscular lever arms. These causes include offset errors, oversizing, rotational errors of femoral or tibial component, instability, maltracking and chondrolysis, patella baja and aseptic loosening. In these cases, reoperation or revision is often necessary.

Keywords Patellar instability $\cdot$ Rotational error $\cdot$ Dynamic valgus $\cdot$ Functional malalignment $\cdot$ Patellar maltracking

\section{Introduction}

According to the literature, the satisfaction rates after total knee arthroplasty (TKA) vary between 75 and $89 \%$ [2, 28, 30, $55,61,79]$. Within the first five years after primary implantation, the revision rate is $2.8 \%$, and the rate of reoperations without exchange of components is $4.3 \%$ [81].

Anterior knee pain is one of the most common causes of persistent problems after implantation of a total knee replacement. It can occur with or without patellar resurfacing. Sensi et al. [69] reported an incidence of $8 \%$ for anterior knee pain after TKA. The intensity of pain is mostly mild to moderate [69]. In this study, no revision had to be performed in any case. Nevertheless, after joint infection, patello-femoral problems are one of the most common reasons for reoperation or revision after TKA [8, 20, 21, 48, 70, 71, 75].

The indication for secondary patellar resurfacing for anterior knee pain should be arrived at with care, because the success rate is stated to vary between only 50 and $60 \%[15$, $17,24,50,51]$. One reason for this observation could be that many other causes of anterior knee pain are responsible besides progression of arthritis and retropatellar cartilage damage.

The causes of anterior knee pain are multifactorial and can be divided into functional (muscle imbalances, dynamic valgus) and mechanical (incorrect positioning of prosthetic 
components, patellar fractures, aseptic loosening, etc.) problems. Many of these problems can be avoided at the primary TKA. However, in every painful TKA an infection should always be ruled out.

The aim of this review article is to summarise knowledge from the literature to provide an overview of this complex subject and present a guide for rational diagnosis.

\section{Can patellar resurfacing prevent anterior knee pain?}

The necessity for patellar resurfacing in TKA is discussed extensively in the literature [12, 22, 58]. Fu et al. [22] conducted a meta-analysis of the efficacy of patellar resurfacing in TKA; ten studies with 1,003 TKA were included. In this study there was no difference in the incidence of anterior knee pain. The risk for reoperation, however, was lower in the resurfacing group than in the group without resurfacing. Similar results were published by He et al. [29]. This meta-analysis included 16 studies with more than 3,000 knee joints. There was no difference between the two groups in terms of anterior knee pain rate, knee pain score, Knee Society knee score and function. The incidence of reoperations in patients without resurfacing was lower than in patients with resurfacing [29]. When only high-quality studies were analysed, there was no difference in reoperation rates between the two groups. From these results, no clear recommendation can currently be made regarding the need for patellar resurfacing regarding the prevention of anterior knee pain.

We see an indication of advanced destructive osteoarthritic changes of the patella with clinical symptoms of anterior knee pain. Otherwise, a "trimming" is carried out with circular synovectomy and denervation. Both methods may be associated with complications which may be a cause of anterior knee pain. A problem of TKA without patellar resurfacing is chondrolysis (see the "Chondrolysis or progression of patella osteoarthritis" section). Problems after patellar resurfacing are aseptic loosening, lateral facet syndrome, fractures or "overstuffing" [25]. An over conservative resection can cause overstuffing with increased tension on the retinacula [25]. Too much resection increases the risk of fracture of the patella. An uncovered lateral facet due to a small or medialised implant may lead to a lateral facet syndrome.

The indication for secondary patellar resurfacing with anterior knee pain should be made with caution, because of reported success rates of 50-60\% [15, 17, 24, 50, 51]. One reason for this observation may be that the cartilage damage of the patella may not be the cause of anterior knee pain. Bhattee et al. [6] have demonstrated that many patients with a poor result after secondary patellar resurfacing have an internal rotational error of the femoral component of more than $3^{\circ}$. Another cause of poor results after secondary patellar resurfacing may be an unrecognised extra-articular pathology [1].

\section{"Natural" course of pain after uncomplicated TKR}

If factors are analysed which may be responsible for anterior knee pain after TKA, it is important to know the natural course of pain after uncomplicated TKA [37]. Brander et al. [11] and Forsythe et al. [23] have studied the intensity of pain after implantation of a simple total knee replacement during the first post-operative year with a visual analogue scale. In the Brander et al. study, the preoperative pain level dropped from an average of 52 points to 25 points after three months. After one year, the pain level was still at an average of 17 points. This was still $32 \%$ of the initial value. Similar findings were stated by Forsythe et al. [23]. In the Forsythe et al. study pain intensity decreased on the visual analogue scale from 68 points to 33 after three months, to 27 after one year and to 22 after two years.

These results are relevant to the development of anterior knee pain after TKA because these series may also include patients with anterior knee pain. The predictors for pain may be divided into modifiable factors and non-modifiable factors. The non-modifiable predictors include the female gender, severe preoperative pain, low pain threshold and young age $[10,37]$. The modifiable predictors include anxiety, depression and problems of pain processing [23]. According to Forsythe et al. [23], patients with increased post-operative pain had a high value on the pain catastrophising scale (PCS). Brander et al. [11] found a correlation to a high anxiety score and depression score. Another predictor for pain after TKR is the preoperative arthritis severity [67].

One problem is certainly in the fulfillment of the preoperative expectations (Fig. 1). Unfulfilled preoperative expectations regarding pain relief within the first post-operative months $[11,23,39]$ may be a cause of fear and uncertainty, factors that may affect the processing of pain. False expectations can be present in particular with regard to pain during certain activities (such as sports). Thus, Bonnin et al. [10] have shown that the incidence of pain in sports such as tennis or golf is generally higher than expected. False expectations may
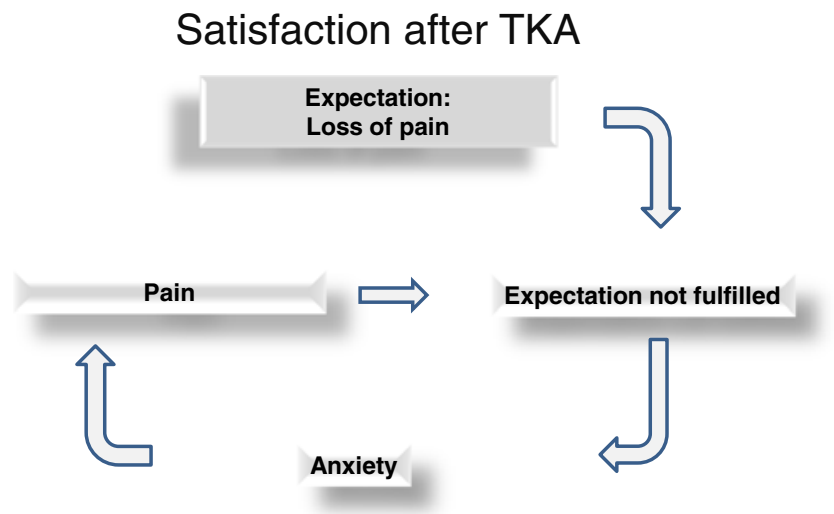

Fig. 1 The vicious cycle if expectations after TKA are not fulfilled 
be a reason for lack of satisfaction after implantation of a total knee replacement.

These findings should be considered when a patient is preoperatively informed about TKA. These facts are also relevant in the diagnosis of anterior knee pain, especially with regard to the indication for revision.

\section{Neurophysiological origin of pain in the patellofemoral joint}

The exact mechanism of how and where anterior knee pain develops is unclear. Different causes may be considered [59]. Today, it is well accepted that one main source for pain sensation are the insertions of the extensor apparatus $[18,19$, 63-65]. Sanchis-Alfonso et al. [63, 64] demonstrated that patients with anterior knee pain had an increased density of nociceptors in the lateral retinaculum. It is likely that disorders of the patellofemoral mechanics lead to local overload of these structures [65]. These mechanical disorders include patellofemoral instability, lateral patellar maltracking or the increased pressure by the extensor mechanism in the sagittal plane. Various causes may be responsible for these three disorders including incorrect positions of the components of the prosthesis, valgus malalignment of the lower extremity and instabilities. Valgus malalignment can be caused by the position of the components or by muscular insufficiencies and imbalances (dynamic valgus) [52, 59].

Local peripatellar synovitis, inflammatory changes in the Hoffa fat pad or osseous oedema can also be considered as causes of anterior knee pain in TKA patients. Van Jonbergen et al. [75] have demonstrated in a systematic review that a peripatellar synovectomy and resection of Hoffa's fat pad have positive effects on pain after TKA.

\section{Functional causes of anterior knee pain after TKA}

Most patellofemoral complaints are mild to moderate and do not require any revision [69]. Many of these problems have no structural but a functional cause and may be related to preoperative osteoarthritis.

It is well known that a preoperative weakness of the quadriceps muscle may persist after TKA. This weakness has significant influence on the movement pattern of the knee [34, 45-47]. It is also known that imbalance of the quadriceps with weakness of the vastus medialis and increased activation of the vastus lateralis muscle can cause a lateral maltracking of the patella $[13,33]$. The preoperative quadriceps weakness caused by osteoarthritis may further deteriorate due to the implantation of a total knee replacement (approaching morbidity) and it may take more than two years until the power of the contralateral limb is reached [66].
Patients with osteoarthritis of the knee often present with additional osteoarthritis of the hip [5]. The weakness of the hip abductors and external rotators can lead to dynamic valgus (Fig. 2) [52, 59]. If the functional disorder of the hip abductors is caused by osteoarthritis, osteoarthritis of the hip should be treated. Sled et al. [73], however, have shown that patients with knee osteoarthritis profit from training the hip abductors.

Dynamic valgus affects the femoropatellar joint because it leads to lateral patellar maltracking $[41,59]$. Dynamic valgus or functional malalignment can be clinically detected with the single leg squat [16].

Many patients after TKA present with a "quadriceps avoidance gait" [36]. This leads to a compensatory increased forward inclination of the trunk [36]. Some patients also have comorbidities of the lumbar spine. A decreased lumbar lordosis leads to increased pelvic tilt and compensatory to increased knee flexion with increased stress on the femoropatellar joint [74]. Tsuji et al. [74] named this condition the knee spine syndrome. Degenerative co-morbidities of the lumbar spine and hip are not uncommon in patients with osteoarthritis. Figure 3 summarises the functional causes of anterior knee pain.

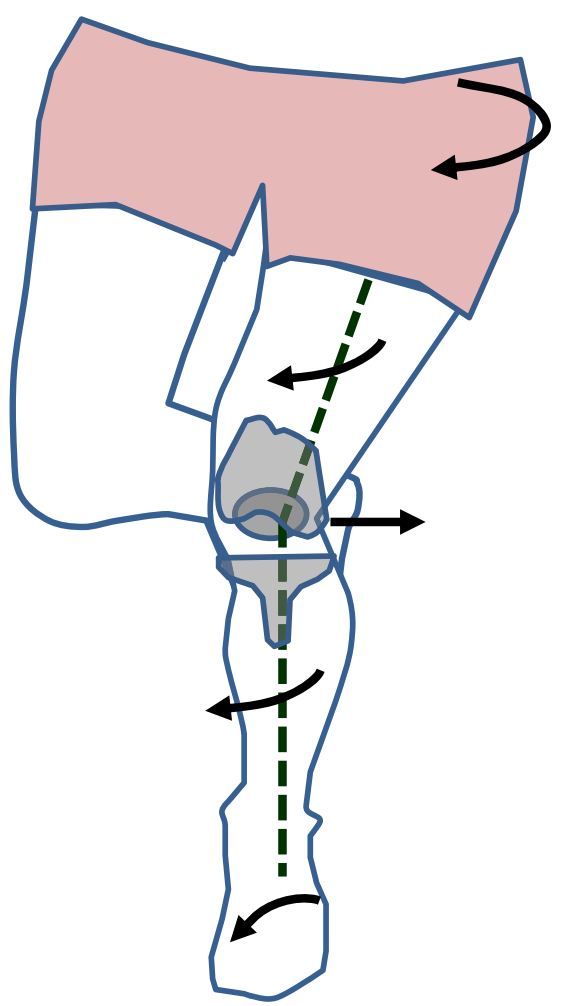

Fig. 2 Schematic drawing of dynamic valgus in patients with TKA. The valgus position of the knee may not be due to incorrect position of the TKA components but rather by internal rotation of the femur and tibia. Internal rotation of the femur can be caused by a weakness of the hip abductors. Internal rotation of the tibia may be a result of rearfoot eversion or pes plano valgus 
Fig. 3 Schematic representation of different factors which contribute to functional patellofemoral problems after TKA

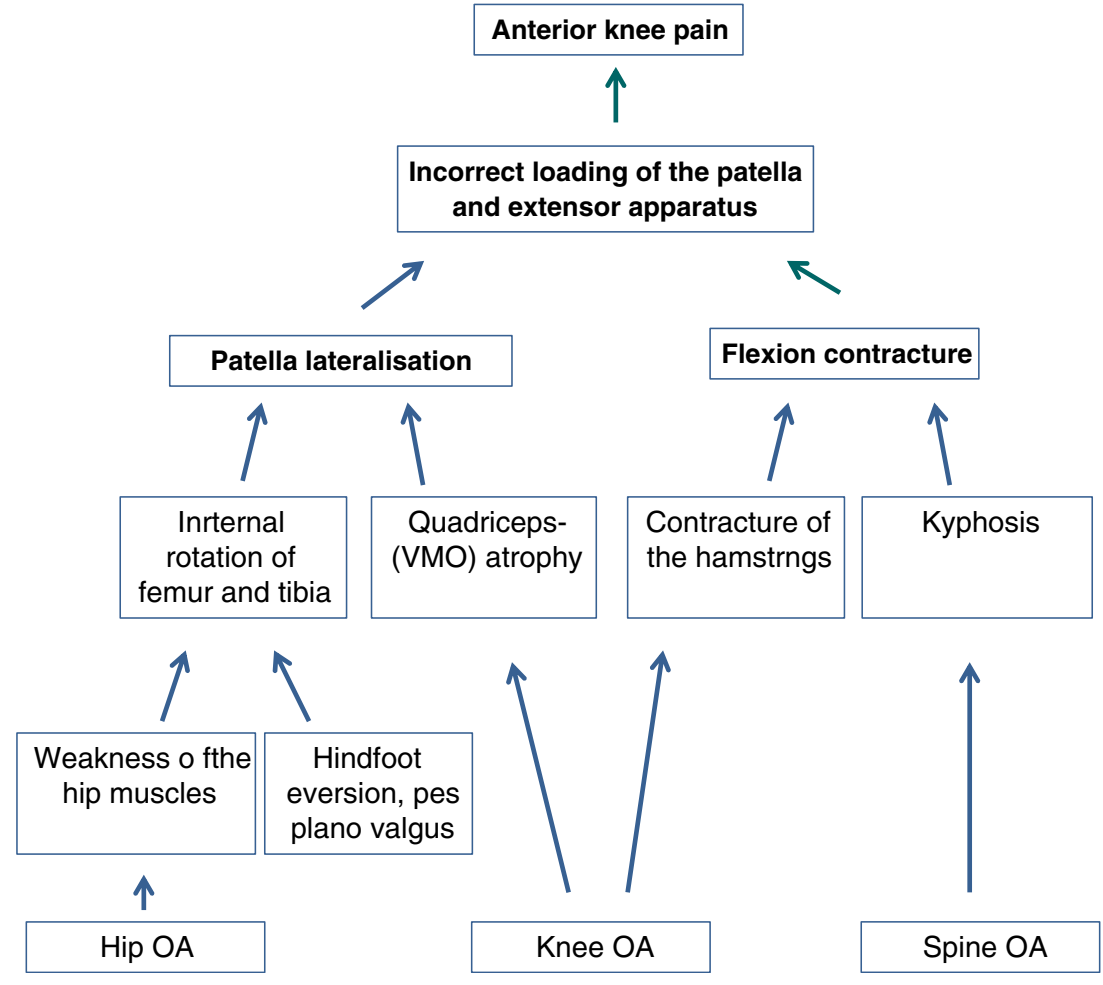

\section{Mechanical causes of anterior knee pain}

The mechanical causes of patello-femoral problems after knee replacement can be distinguished according to whether they increase instability in the joint, lead to changes in the transmission of the joint pressure or whether they affect the muscular lever arms. These factors are patello-femoral instability, prosthesis design, patella baja, chondrolysis, offset error of the femoral component rotational error, tibiofemoral instability, avascular necrosis and synovial hyperplasia. All of these causes can lead to pain and functional deficits of patients with anterior knee pain after TKA.

Patello-femoral instability and maltracking

Patello-femoral instability is a common cause of postoperative pain and functional limitations in the joint, which may lead to revision surgery [43]. The reported revision rates for patello-femoral instability after TKA are about $1 \%[59$, 66]. To be precise, when talking about patellar instability after TKA most authors mean maltracking rather than recurrent dislocations [60, 68] (Fig. 4). A dislocation after TKA is considered to be a very rare event.

The causes of maltracking can be either insufficient soft tissue balancing or component positioning (patella, femoral rotation, valgus malalignment) [49]. However, the design of the femoral component or the patella may also influence the stability of the patella [70]. It has been shown that the depth of the trochlea is proportional to the stability of the patella and the transmitted forces in the patellofemoral joint [80]. An asymmetrical femoral bearing with lateral elevation leads to a more stable experimental patellar tracking as a flat slide bearing, particularly for more than $45^{\circ}$ of flexion [80], but also a preoperatively increased tibial tubercle-trochlear groove (TTTG) distance or patella alta can cause instabilities.

Patello-femoral instability or maltracking is usually diagnosed by conventional X-ray (Merchant view) which can demonstrate patella lateralisation, tilting of the patella or a lateral osteophyte (Fig. 4). It is important to note that a lateral osteophyte is able to fix a maltracking of the patella.

Influence of prosthetic designs

The prosthetic design can also play a role in the development of patellofemoral problems, but not only the design of the patello-femoral joint has an impact on the development of anterior knee problems but it has also been shown that femoral

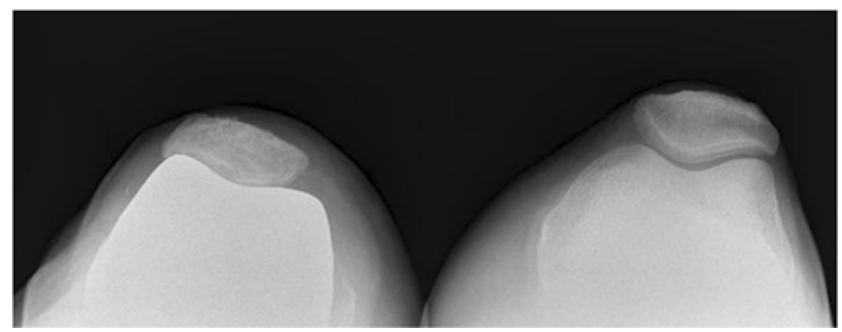

Fig. 4 Patellar maltracking with a lateral osteophyte and increased tilt in a patient with anterior knee pain after TKA 
components with a posterior centre of rotation have a favourable influence on anterior knee pain [75].

The degree of coupling may also have an influence on the pressure in the transmission patello-femoral joint. Becher et al. [9] have shown that a posterior stabilised (PS) prosthesis design leads to lower patellofemoral joint pressures than a cruciate-retaining (CR) design. This mechanism should be considered when the patient presents with posterior instability and anterior knee pain after TKA. In a recent meta-analysis, however, no difference was found with regard to postoperative pain between CR prostheses and PS designs [35].

Patella baja

Patella baja (Fig. 5) can also lead to anterior knee pain after TKA [14]. The incidence of patella baja after TKA or unicompartmental arthroplasty is low [3, 72]. Sharma et al. [72] studied 135 consecutive patients after TKA with respect to the patellar height. In this study, only one patient developed a post-operative patella baja by definition (Insall-Salvati ratio of less than 0.8). Five patients had a considerable decrease of the Insall-Salvati ratio by $10 \%$. Risk factors for the development of patella baja after unicompartmental knee arthroplasty are age over 65 , male gender and the implementation of a special rehabilitation programme [3]. Patella baja after TKA may be acquired or congenital [14]. Post-operative patella baja may be caused by scarring or contracture of the patellar tendon above the tibial tuberosity. It has been argued that patella eversion can contribute to the development of patella baja. A pseudo-patella baja may arise from an elevated joint line. That means that the patella is in its normal position in relation to the trochlea, but the distance between the patella and the tibia is reduced. A pseudo-patella baja may be the result of a femoral or tibial over-resection with a high inlay. Patella baja can be a problem

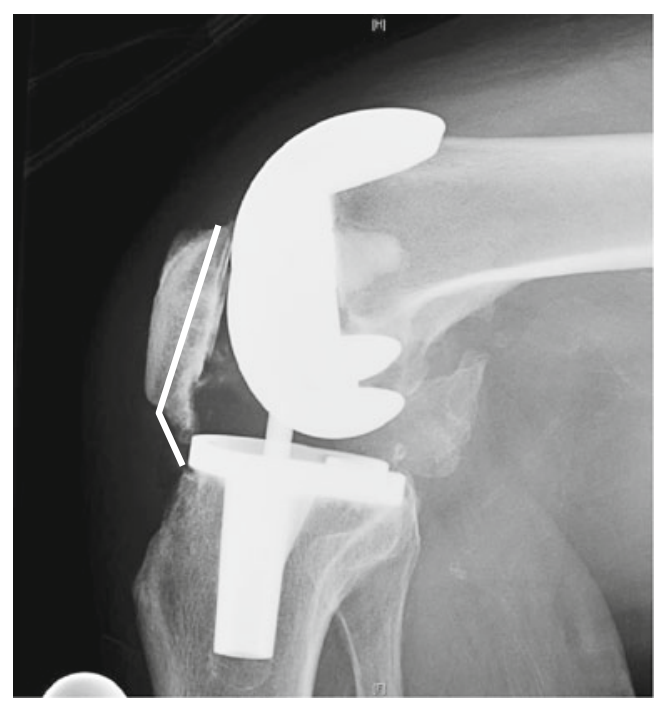

Fig. 5 Extreme patella baja after TKA in a patient with anterior knee pain. The Caton Index is far below 1 for revision procedures because in these cases an osteotomy of the tibial tuberosity is often required to expose the joint [14].

\section{Chondrolysis or progression of patella osteoarthritis}

In TKA without patellar resurfacing a progression of chondrolysis can lead to patellofemoral pain [70]. The chondrolysis may be the continuation of the osteoarthritic process, but can also be associated with mechanical factors that are attributable to the knee prosthesis implantation (e.g. malrotation of the components).

\section{Offset errors of the femoral component}

The anterior offset of the femoral component has a major impact on the mechanics of the patellofemoral joint. An anterior overhang can be caused by selection of a femoral component that is too large [31] or an overly minimal anterior resection (overstuffing). This can lead to increased pressure of the patella and its surrounding structures [69].

However, an increased anterior resection ("undercutting", "notching") can also lead to patellofemoral problems. In this case, the passive quadriceps insufficiency may be a cause of anterior knee pain. Increased posterior offset can also lead to flexion deficit which might also influence the contact pressure in the femoropatellar joint.

\section{Rotational error of the femoral or tibial component}

Various studies have shown that an internally rotated femoral or tibial component can cause an increased lateral tilt angle and a lateralisation of the patella $[4,6,7,8,32]$. Some authors see incorrect rotation of the femoral component as the most common cause of patellar complications after TKA $[4,6]$. Even an internal rotation of the femoral component of 3-7 can lead to chronic problems $[4,8,32,62,76]$. Bhattee et al. [6] have demonstrated that poor results after a secondary patellar resurfacing are often due to rotational error of the femoral component.

An internal rotational error of the tibial component can also lead to patello-femoral problems [54]. In the series of Nicoll and Rowley [54] more than half of the 38 patients with a fixed bearing had an internal rotational error of femoral and tibial components. In contrast to the internal rotation of the tibial component external rotational errors were well tolerated. Based on these findings, a rotary computed tomography (CT) scan should be obtained in patients with anterior knee pain when no other causes are evaluable.

Tibio-femoral instability

As stated above, a posterior tibio-femoral instability, manifested especially in flexion, can affect the patello-femoral joint 


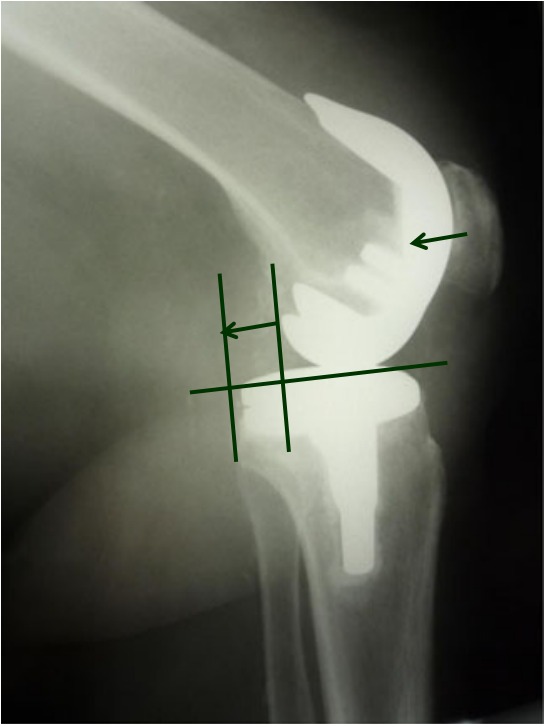

Fig. 6 Lateral X-ray of a patient with anterior knee pain after TKA. Posterior tibial subluxation causes increased patellofemoral joint contact pressure

because the joint contact pressure is increased due to the posterior subluxation (Fig. 6). Causes of flexion instability are an increased tibial slope or iatrogenic or traumatic injury to the posterior soft tissue stabilisers (posterior cruciate ligament, posteromedial and posterolateral corner joint) [57].

\section{Avascular necrosis}

Localised pain over the patella under load may indicate avascular necrosis or a transient ischaemia $[44,70,78]$. The incidence of symptomatic ischaemic necrosis is low. However, up to $10 \%$ of patients after TKA have a pathological femoral radionuclide uptake in the patella during the post-operative period [66]. According to Gelfer et al. [26] the incidence of ischaemic episodes in patients without lateral release is $19.5 \%$. In patients in whom lateral release was necessary, the incidence is probably even higher [44]. However, intraosseous blood flow does not correlate well with post-operative anterior knee pain [33].

\section{Patellar fracture}

Patellar fracture is a rather rare complication after TKA with a prevalence of $0.68 \%$ [56]. When the extensor mechanism is intact and the patellar implant is stable fractures can be treated conservatively (type I fractures) (Fig. 7). An insufficiency of the extensor mechanism usually requires a surgical procedure (type II fracture). A fracture that is associated with a loosened resurfacing also requires a surgical procedure (type III fracture).

Patellar clunk

"Patellar clunk" is a soft tissue impingement in the intercondylar notch. The cause is a fibrous knot above the patella which
Fig. 7 Type I patellar fracture after TKA with dislocation but stable implant

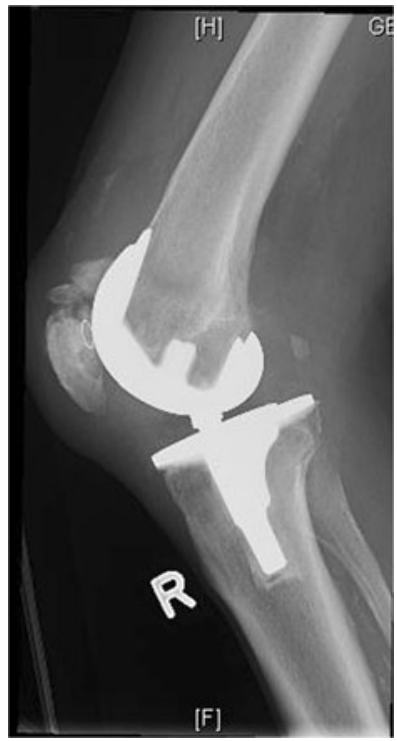

impinges in flexion on the roof of the intercondylar notch $[18$, $38,42]$. The incidence of this phenomenon was more common in older prosthetic models. Today, it is only rarely observed.

\section{Synovial hyperplasia}

Synovial hyperplasia can also lead to impingement in the patello-femoral joint [18] (Fig. 8). Synovial hyperplasia may be a result of a persistent post-operative irritation. Nevertheless, it is important to exclude infections or metal hypersensitivity [40, 41].

\section{Treatment of anterior knee pain after TKA}

Therapy of anterior knee pain after TKA depends on the causes, pain intensity and functional impairment. One can distinguish between functional causes and mechanical causes. For functional causes non-operative treatment is the treatment of choice.

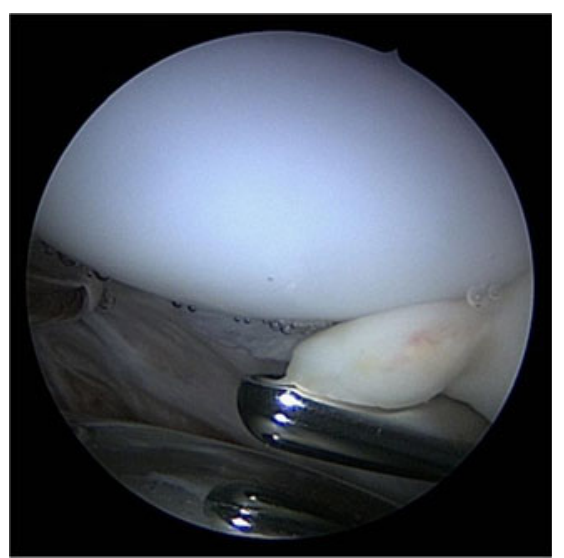

Fig. 8 Plica impingement between resurfaced patella and femoral component 
For mechanical causes surgical treatment may be indicated. Therefore, mechanical causes should always be excluded before therapy planning. Figure 9 shows an algorithm for the diagnostics to exclude mechanical causes of anterior knee pain after TKA.

\section{Therapy for functional causes}

When anterior knee pain is related to functional problems, exercise is the treatment of choice (Fig. 10) [27]. A systematic review has shown that physical therapy in patients with anterior knee pain should address not only the quadriceps, but also hip and trunk muscles to correct the dynamic valgus or functional malalignment [26]. Nakagawa et al. [53] reported that with a combination of quadriceps, hip and trunk stabilisation training a significantly better effect can be achieved than with quadriceps training alone.

There is also evidence that the functional maltracking of the patella can be corrected temporarily with tape or with knee braces which apply a medially directed force on the patella [77]. It has been shown that tape or brace application has a positive effect on anterior knee pain. Tape or brace treatment should support the correction of dynamic valgus by exercise. A synergistic effect has been reported for the combination of exercise and tape [27].

\section{Therapy for mechanical causes}

If there are mechanical problems, surgical treatment may be indicated. However, due to the natural course of pain [11, 23]

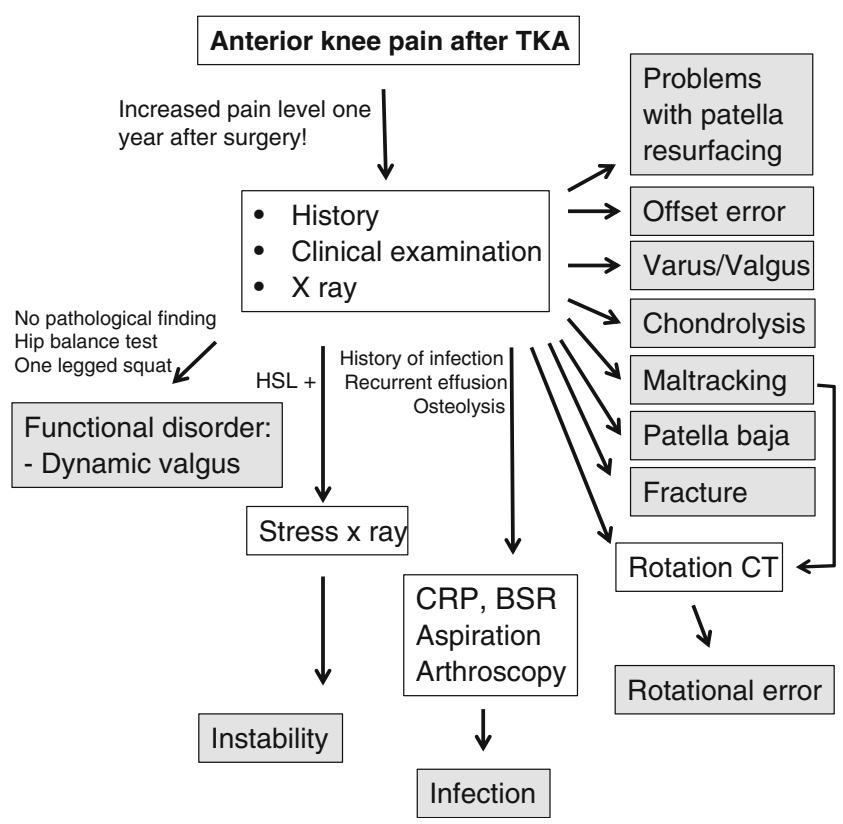

Fig. 9 Diagnostic and therapeutic algorithm for anterior knee pain after TKA

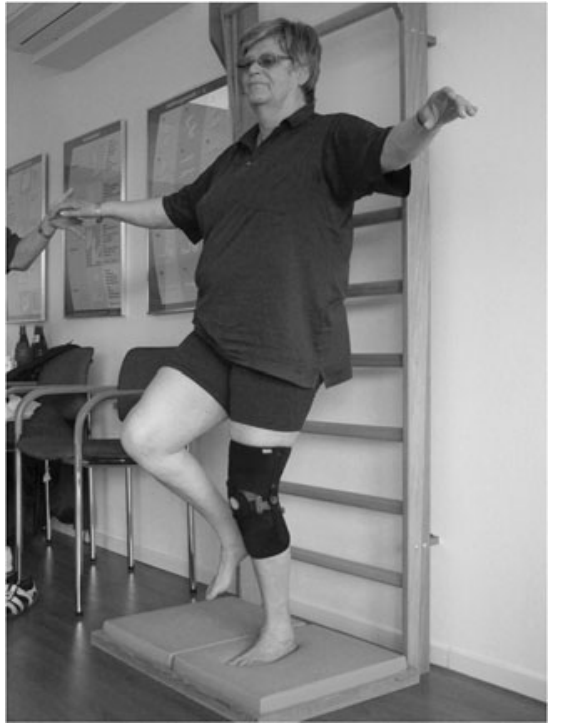

Fig. 10 One legged exercise for functional patella problems after TKA. The knee is slightly flexed and the patient is advised to keep the leg axis straight. This exercise trains the hip abductors and external rotators. To correct patellar maltracking, a patella brace which applies a medially directed force on the patella is used (Patella Pro, Otto Bock, Duderstadt, Germany)

the indication for surgery should be made with caution within the first post-operative year. Many patients with mechanical causes of anterior knee pain may also have additional functional problems. Therefore, especially in patients with only mild pain or functional impairment, a conservative therapy trial may be indicated.

We distinguish between revision surgery with exchange or replacement of components of the prosthesis, secondary patellar resurfacing and non-revision reoperations (arthrolysis, synovectomy, lateral release).

\section{Revision}

Revision surgery should be considered in patients with incorrectly positioned components (offset and rotational errors), instabilities or aseptic loosening of a patellar resurfacing. Bone loss in cases with offset or rotation corrections can be compensated for with a metal spacer. Therefore, modular revision implants should always be available. In cases with tibio-femoral instability revision with implantation of a model with a higher degree of coupling may be necessary (e.g. change in posterior instability of CR on PS).

\section{Secondary patellar resurfacing}

In cases with retropatellar chondrolysis or progressive osteoarthritis the indication for secondary resurfacing should be made cautiously, since in the literature success rates of $66 \%$ are given $[12,15,22,29,58]$. 
If the patella plug is incorrectly positioned a revision with a new resurfacing should be considered. In cases with an overstuffed patella the patella plug should be changed and additional bone should be resected. In a lateral facet syndrome, a change of the patella plug or secondary patellar resurfacing should be considered.

\section{Non-revision reoperations}

For non-revision surgery arthroscopy plays an important role. In cases of a "maltracking" with lateralisation and increased "tilt" angle an arthroscopic lateral release with peripatellar synovectomy should be considered. Synovectomy and localized arthrolysis may also be a treatment option for cases with peripatellar adhesion or for patellar clunk syndrome. Even lateral patellar osteophytes can be resected arthroscopically. Arthroscopy may also play a role in the diagnostics of lowgrade infections after TKA (history of recurrent swelling). The microbiological and histological analyses of multiple biopsies have a higher sensitivity and specificity than aspiration. One should keep in mind that each case of anterior knee pain can be triggered by an infection.

We do not recommend reconstruction of the medial patellofemoral ligament (MPFL) in patients with patellar instability after TKA since these patients do not suffer from patellar dislocations rather than from lateralisation or subluxation. The cause of instability is mostly an incorrect positioning of the components (rotational or valgus error). MPFL reconstruction with an autologous tendon graft may increase the patellofemoral contact pressure.

A patella baja can be corrected by an osteotomy of the tibial tuberosity. With this procedure a proximalisation of one to two centimetres can be achieved.

Open Access This article is distributed under the terms of the Creative Commons Attribution License which permits any use, distribution, and reproduction in any medium, provided the original author(s) and the source are credited.

\section{References}

1. Al-Hadithy N, Rozati H, Sewell MD, Dodds AL, Brooks P, Chatoo M (2012) Causes of a painful total knee arthroplasty. Are patients still receiving total knee arthroplasty for extrinsic pathologies? Int Orthop 36(6):1185-1189. doi:10.1007/s00264-011-1473-6

2. Anderson JG, Wixson RL, Tsai D, Stulberg SD, Chang RW (1996) Functional outcome and patient satisfaction in total knee patients over the age of 75. J Arthroplasty 11(7):831-840

3. Anagnostakos K, Lorbach O, Kohn D (2012) Patella baja after unicompartmental knee arthroplasty. Knee Surg Sports Traumatol Arthrosc 20(8):1456-1462

4. Akagi M, Matsusue Y, Mata T, Asada Y, Horiguchi M, Iida H, Nakamura T (1999) Effect of rotational alignment on patellar tracking in total knee arthroplasty. Clin Orthop 366:155-163
5. Astephen JL, Deluzio KJ, Caldwell GE, Dunbar MJ, Hubley-Kozey CL (2008) Gait and neuromuscular pattern changes are associated with differences in knee osteoarthritis severity levels. J Biomech 41(4):868-876

6. Bhattee G, Moonot P, Govindaswamy R, Pope A, Fiddian N, Harvey A (2013) Does malrotation of components correlate with patient dissatisfaction following secondary patellar resurfacing? Knee. doi: 10.1016/j.knee.2012.12.006. [Epub ahead of print]

7. Barrack RL, Schrader T, Bertot AJ, Wolfe MW, Myers L (2001) Component rotation and anterior knee pain after total knee arthroplasty. Clin Orthop 392:46-55

8. Berger RA, Crossett LS, Jacobs JJ, Rubash HE (1998) Malrotation causing patellofemoral complications after total knee arthroplasty. Clin Orthop 356:144-153

9. Becher C, Heyse TJ, Kron N, Ostermeier S, Hurschler C, Schofer MD, Fuchs-Winkelmann S, Tibesku CO (2009) Posterior stabilized TKA reduce patellofemoral contact pressure compared with cruciate retaining TKA in vitro. Knee Surg Sports Traumatol Arthrosc 17(10): $1159-1165$

10. Bonnin MP, Basiglini L, Archbold HA (2011) What are the factors of residual pain after uncomplicated TKA? Knee Surg Sports Traumatol Arthrosc 19(9):1411-1417

11. Brander VA, Stulberg SD, Adams AD, Harden RN, Bruehl S, Stanos SP, Houle T (2003) Predicting total knee replacement pain: a prospective, observational study. Clin Orthop 416:27-36

12. Chen K, Li G, Fu D, Yuan C, Zhang Q, Cai Z (2013) Patellar resurfacing versus nonresurfacing in total knee arthroplasty: a metaanalysis of randomised controlled trials. Int Orthop 37(6):1075-1083

13. Chester R, Smith TO, Sweeting D, Dixon J, Wood S, Song F (2008) The relative timing of $\mathrm{VMO}$ and $\mathrm{VL}$ in the aetiology of anterior knee pain: a systematic review and meta-analysis. BMC Musculoskelet Disord 9:64. doi:10.1186/1471-2474-9-64

14. Chonko DJ, Lombardi AV Jr, Berend KR (2004) Patella baja and total knee arthroplasty (TKA): etiology, diagnosis, and management. Surg Technol Int 12:231-238

15. Correia J, Sieder M, Kendoff D, Citak M, Gehrke T, Klauser W, Haasper C (2012) Secondary patellar resurfacing after primary bicondylar knee arthroplasty did not meet patients' expectations. Open Orthop J 6:414-418

16. Crossley KM, Zhang WJ, Schache AG, Bryant A, Cowan SM (2011) Performance on the single-leg squat task indicates hip abductor muscle function. Am J Sports Med 39:866-873

17. Daniilidis K, Vogt B, Gosheger G, Henrichs M, Dieckmann R, Schulz D, Hoell S (2012) Patellar resurfacing as a second stage procedure for persistent anterior knee pain after primary total knee arthroplasty. Int Orthop 36(6):1181-1183. doi:10.1007/s00264-011-1463-8

18. Dajani KA, Stuart MJ, Dahm DL, Levy BA (2010) Arthroscopic treatment of patellar clunk and synovial hyperplasia after total knee arthroplasty. J Arthroplasty 25:97-103

19. Dye SF (2005) The pathophysiology of patellofemoral pain: a tissue homeostasis perspective. Clin Orthop Relat Res 436:100-110

20. Eisenhuth SA, Saleh KJ, Cui Q, Clark CR, Brown TE (2006) Patellofemoral instability after total knee arthroplasty. Clin Orthop Relat Res 446:149-160

21. Fehring TK, Odum S, Griffin WL, Mason JB, Nadaud M (2001) Early failures in total knee arthroplasty. Clin Orthop Relat Res 392:315-318

22. Fu Y, Wang G, Fu Q (2011) Patellar resurfacing in total knee arthroplasty for osteoarthritis: a meta-analysis. Knee Surg Sports Traumatol Arthrosc 19(9):1460-1466

23. Forsythe ME, Dunbar MJ, Hennigar AW, Sullivan MJ, Gross M (2008) Prospective relation between catastrophizing and residual pain following knee arthroplasty: two-year follow-up. Pain Res Manag 13(4):335-341

24. Garcia RM, Kraay MJ, Goldberg VM (2010) Isolated resurfacing of the previously unresurfaced patella total knee arthroplasty. J Arthroplasty 25(5):754-758. doi:10.1016/j.arth.2009.06.01 
25. Ghosh KM, Merican AM, Iranpour F, Deehan DJ, Amis AA (2009) The effect of overstuffing the patellofemoral joint on the extensor retinaculum of the knee. Knee Surg Sports Traumatol Arthrosc 17(10):1211-1216

26. Gelfer Y, Pinkas L, Horne T, Halperin N, Alk D, Robinson D (2003) Symptomatic transient patellar ischemia following total knee replacement as detected by scintigraphy. A prospective, randomized, doubleblind study comparing the mid-vastus to the medial para-patellar approach. Knee 10:341-345

27. Harvie D, O'Leary T, Kumar S (2011) A systematic review of randomized controlled trials on exercise parameters in the treatment of patellofemoral pain: what works? J Multidiscip Healthc 4:383392

28. Hawker G, Wright J, Coyte P, Paul J, Dittus R, Croxford R, Katz B, Bombardier C, Heck D, Freund D (1998) Health-related quality of life after knee replacement. J Bone Joint Surg Am 80(2):163-173

29. He JY, Jiang LS, Dai LY (2011) Is patellar resurfacing superior than nonresurfacing in total knee arthroplasty? A meta-analysis of randomized trials. Knee 18(3):137-144

30. Heck DA, Robinson RL, Partridge CM, Lubitz RM, Freund DA (1998) Patient outcomes after knee replacement. Clin Orthop Relat Res 356:93-110

31. Kawahara S, Matsuda S, Fukagawa S, Mitsuyasu H, Nakahara H, Higaki H, Shimoto T, Iwamoto Y (2012) Upsizing the femoral component increases patellofemoral contact force in total knee replacement. J Bone Joint Surg Br 94(1):56-61

32. Kessler O, Patil S, Colwell CW Jr, D'Lima DD (2008) The effect of femoral component malrotation on patellar biomechanics. J Biomech 41(16):3332-3339

33. Kohl S, Evangelopoulos DS, Hartel M, Kohlhof H, Roeder C, Eggli S (2011) Anterior knee pain after total knee arthroplasty: does it correlate with patellar blood flow? Knee Surg Sports Traumatol Arthrosc 19(9): 1453-1459

34. Lin F, Wilson NA, Makhsous M, Press JM, Koh JL, Nuber GW, Zhang LQ (2010) In vivo patellar tracking induced by individual quadriceps components in individuals with patellofemoral pain. $\mathrm{J}$ Biomech 43(2):235-241

35. Li N, Tan Y, Deng Y, Chen L (2012) Posterior cruciate-retaining versus posterior stabilized total knee arthroplasty: a meta-analysis of randomized controlled trials. Knee Surg Sports Traumatol Arthrosc. [Epub ahead of print] PMID: 23117166

36. Li K, Ackland DC, McClelland JA, Webster KE, Feller JA, de Steiger R, Pandy MG (2013) Trunk muscle action compensates for reduced quadriceps force during walking after total knee arthroplasty. Gait Posture 38:79-85

37. Liu SS, Buvanendran A, Rathmell JP, Sawhney M, Bae JJ, Moric M, Perros S, Pope AJ, Poultsides L, Della Valle CJ, Shin NS, McCartney CJ, Ma Y, Shah M, Wood MJ, Manion SC, Sculco TP (2012) Predictors for moderate to severe acute postoperative pain after total hip and knee replacement. Int Orthop 36(11):2261-2267

38. Lucas TS, DeLuca PF, Nazarian DG, Bartolozzi AR, Booth RE Jr (1999) Arthroscopic treatment of patellar clunk. Clin Orthop 367: 226-229

39. Lundblad H, Kreicbergs A, Jansson KA (2008) Prediction of persistent pain after total knee replacement for osteoarthritis. J Bone Joint Surg Br 90:166-171

40. Lützner J, Hartmann A, Dinnebier G, Spornraft-Ragaller P, Hamann C, Kirschner S (2013) Metal hypersensitivity and metal ion levels in patients with coated or uncoated total knee arthroplasty: a randomised controlled study. Int Orthop. [Epub ahead of print]

41. MacIntyre NJ, Hill NA, Fellows RA, Ellis RE, Wilson DR (2006) Patellofemoral joint kinematics in individuals with and without patellofemoral pain syndrome. J Bone Joint Surg Am 88(12): 2596-2605

42. Maloney WJ, Schmidt R, Sculco TP (2003) Femoral component design and patellar clunk syndrome. Clin Orthop 410:199-202
43. Malo M, Vince KG (2003) The unstable patella after total knee arthroplasty: etiology, prevention, and management. J Am Acad Orthop Surg 11:364-371

44. McMahon MS, Scuderi GR, Glashow JL, Scharf SC, Meltze LP, Scott WN (1990) Scintigraphic determination of patellar viability after excision of infrapatellar fat pad and/or lateral retinacular release in total knee arthroplasty. Clin Orthop Relat Res 260:10-16

45. Mizner RL, Petterson SC, Snyder-Mackler L (2005) Quadriceps strength and the time course of functional recovery after total knee arthroplasty. J Orthop Sports Phys Ther 35:424-436

46. Mizner RL, Petterson SC, Stevens JE, Axe MJ, Snyder-Mackler L (2005) Preoperative quadriceps strength predicts functional ability one year after total knee arthroplasty. J Rheumatol 32:1533-1539

47. Mizner RL, Snyder-Mackler L (2005) Altered loading during walking and sit-to-stand is affected by quadriceps weakness after total knee arthroplasty. J Orthop Res 23:1083-1090

48. Mochizuki RM, Schurman DJ (1979) Patellar complications following total knee arthroplasty. J Bone Joint Surg Am 61:879-883

49. Motsis EK, Paschos N, Pakos EE, Georgoulis AD (2009) Patellar instability after total knee arthroplasty. J Orthop Surg (Hong Kong) 17:351-357

50. Muñoz-Mahamud E, Popescu D, Nuñez E, Lozano LM, Nuñez M, Sastre S, Torner P, Segur JM, Maculé F (2011) Secondary patellar resurfacing in the treatment of patellofemoral pain after total knee arthroplasty. Knee Surg Sports Traumatol Arthrosc 19(9):1467-1472

51. Muoneke HE, Khan AM, Giannikas KA, Hägglund E, Dunningham TH (2003) Secondary resurfacing of the patella for persistent anterior knee pain after primary knee arthroplasty. J Bone Joint Surg Br 85(5):675-678

52. Myer GD, Ford KR, Barber Foss KD, Goodman A, Ceasar A, Rauh MJ, Divine JG, Hewett TE (2010) The incidence and potential pathomechanics of patellofemoral pain in female athletes. Clin Biomech (Bristol, Avon) 25(7):700-707

53. Nakagawa T, Muniz T, Baldon Rde M, Dias Maciel C, de Menezes Reiff RB, Serrão FV (2008) The effect of additional strengthening of hip abductor and lateral rotator muscles in patellofemoral pain syndrome: a randomised controlled pilot study. Clin Rehabil 22(12): $1051-1060$

54. Nicoll D, Rowley DI (2010) Internal rotational error of the tibial component is a major cause of pain after total knee replacement. $\mathrm{J}$ Bone Joint Surg Br 92:1238-1244

55. Noble PC, Gordon MJ, Weiss JM, Reddix RN, Conditt MA, Mathis KB (2005) Does total knee replacement restore normal knee function? Clin Orthop Relat Res 431:157-165

56. Ortiguera CJ, Berry DJ (2002) Patellar fracture after total knee arthroplasty. J Bone Joint Surg Am 84:532-540

57. Pagnano MW, Hanssen AD, Lewallen DG, Stuart MJ (1998) Flexion instability after primary posterior cruciate retaining total knee arthroplasty. Clin Orthop 356:39-46

58. Patel K, Raut V (2011) Patella in total knee arthroplasty: to resurface or not to-a cohort study of staged bilateral total knee arthroplasty. Int Orthop 35(3):349-353

59. Petersen W, Ellermann A, Liebau C, Brüggemann GP, Best R, Gösele-Koppenburg A, Semsch H, Albasini A, Rembitzki I (2010) Das patellofemorale Schmerzsyndrom. Orthop Prax 46(8):34-42

60. Rand JA (1994) The patellofemoral joint in total knee arthroplasty. J Bone Joint Surg Am 76:612-620

61. Robertsson O, Dunbar M, Pehrsson T, Knutson K, Lidgren L (2000) Patient satisfaction after knee arthroplasty: a report on 27,372 knees operated on between 1981 and 1995 in Sweden. Acta Orthop Scand 71(3):262-267

62. Romero J, Duronio JF, Sohrabi A, Alexander N, MacWilliams BA, Jones LC, Hungerford DS (2002) Varus and valgus flexion laxity of total knee alignment methods on loaded cadaveric knees. Clin Orthop 394:243-253

63. Sanchis-Alfonso V, Roselló-Sastre E, Monteagudo-Castro C, Esquerdo J (1998) Quantitative analysis of nerve changes in the 
lateral retinaculum in patients with isolated symptomatic patellofemoral malalignment. A preliminary study. Am J Sports Med 26(5):703-709

64. Sanchis-Alfonso V, Roselló-Sastre E (2000) Immunohistochemical analysis for neural markers of the lateral retinaculum in patients with isolated symptomatic patellofemoral malalignment. A neuroanatomic basis for anterior knee pain in the active young patient. Am J Sports Med 28(5):725-731

65. Sanchis-Alfonso V (2008) Patellofemoral pain. Orthopade 37(9): 835-836, 838-40

66. Saleh KJ, Lee LW, Gandhi R, Ingersoll CD, Mahomed NN, SheibaniRad S, Novicoff WM, Mihalko WM (2010) Quadriceps strength in relation to total knee arthroplasty outcomes. Instr Course Lect 59:119 130

67. Schnurr C, Jarrous M, Güdden I, Eysel P, König DP (2013) Preoperative arthritis severity as a predictor for total knee arthroplasty patients' satisfaction. Int Orthop 37(7):1257-1261

68. Scuderi GR, Insall JN, Scott NW (1994) Patellofemoral pain after total knee arthroplasty. J Am Acad Orthop Surg 2:239-246

69. Sensi L, Buzzi R, Giron F, De Luca L, Aglietti P (2011) Patellofemoral function after total knee arthroplasty: gender-related differences. J Arthroplasty 26(8):1475-1480

70. Seil R, Pape D (2011) Causes of failure and etiology of painful primary total knee arthroplasty. Knee Surg Sports Traumatol Arthrosc 19(9):1418-1432

71. Sharkey PF, Hozack WJ, Rothman RH, Shastri S, Jacoby SM (2002) Insall Award paper. Why are total knee arthroplasties failing today? Clin Orthop Relat Res 404:7-13

72. Sharma V, Tsailas PG, Maheshwari AV, Ranawat AS, Ranawat CS (2008) Does patellar eversion in total knee arthroplasty cause patella baja? Clin Orthop Relat Res 466(11):2763-2768

73. Sled EA, Khoja L, Deluzio KJ, Olney SJ, Culham EG (2010) Effect of a home program of hip abductor exercises on knee joint loading, strength, function, and pain in people with knee osteoarthritis: a clinical trial. Phys Ther 90(6):895-904

74. Tsuji T, Matsuyama Y, Goto M, Yimin Y, Sato K, Hasegawa Y, Ishiguro N (2002) Knee-spine syndrome: correlation between sacral inclination and patellofemoral joint pain. J Orthop Sci 7(5):519-523

75. van Jonbergen HP, Reuver JM, Mutsaerts EL, Poolman RW (2012) Determinants of anterior knee pain following total knee replacement: a systematic review. Knee Surg Sports Traumatol Arthrosc. [Epub ahead of print] PMID:23160846

76. Verlinden C, Uvin P, Labey L, Luyckx JP, Bellemans J, Vandenneucker H (2010) The influence of malrotation of the femoral component in total knee replacement on the mechanics of patellofemoral contact during gait: an in vitro biomechanical study. J Bone Joint Surg Br 92:737-742

77. Warden SJ, Hinman RS, Watson MA Jr, Avin KG, Bialocerkowski $\mathrm{AE}$, Crossley KM (2008) Patellar taping and bracing for the treatment of chronic knee pain: a systematic review and meta-analysis. Arthritis Rheum 59(1):73-83. doi:10.1002/art.23242

78. Wetzner SM, Bezreh JS, Scott RD, Bierbaum BE, Newberg AH (1985) Bone scanning in the assessment of patellar viability following knee replacement. Clin Orthop Relat Res 199:215-219

79. Wylde V, Learmonth I, Potter A, Bettinson K, Lingard E (2008) Patient-reported outcomes after fixed- versus mobile-bearing total knee replacement: a multi-centre randomised controlled trial using the Kinemax total knee replacement. J Bone Joint Surg Br 90(9): 1172-1179

80. Yoshii I, Whiteside LA, Anouchi YS (1992) The effect of patellar button placement and femoral component design on patellar tracking in total knee arthroplasty. Clin Orthop Relat Res 275:211-221

81. Zmistowski B, Restrepo C, Kahl LK, Parvizi J, Sharkey PF (2011) Incidence and reasons for nonrevision reoperation after total knee arthroplasty. Clin Orthop Relat Res 469:138-145 